\title{
Shearer's wrist: the carpal tunnel syndrome as an occupational disease in professional sheep shearers
}

\author{
Fergal P Monsell, Roger M Tillman
}

Compression neuropathy of the median nerve in the carpal tunnel, better known as the carpal tunnel syndrome, occurs most commonly in adults aged between 30 and 60 years of age, and is five times more common in women than men. ${ }^{1}$

Any condition that crowds or reduces the capacity of the carpal tunnel may initiate the symptoms. Local causes include malaligned Colles' fracture, oedema from trauma or infection, and tumours such as ganglia, lipomata or xanthomata. Systemic conditions associated with the syndrome include diabetes mellitus, myxoedema, amyloidosis, pregnancy, rheumatoid arthritis, acromegaly, and obesity.

Several well documented specific occupations causing carpal tunnel syndrome have also been described including dental hygienists, ${ }^{2}$ meat packers, ${ }^{3}$ butchers, ${ }^{4}$ and garment workers. ${ }^{5}$ No relation between the occupation of sheep shearing and carpal tunnel syndrome has previously been described, however.

\section{Case report}

A 29 year old man presented at clinic with a two month history of parasthesia in the left hand. Clinical examination of the hand showed sensory disturbance over the median nerve distribution but no weakness, and a clinical diagnosis of carpal tunnel syndrome was made.

His occupation was that of professional sheep shearer to the level of being ranked third in the world in competitive shearing. He commented that many of his colleagues had complained of similar problems.

Nerve conduction studies confirmed the diagnosis and surgical decompression of the carpal tunnel was performed. Subsequently his symptoms resolved and he returned to top class shearing.

Department of Orthopaedics, Royal Preston Hospital, Sharoe Green Lane, Preston PR2 4HT

F P Monsell

Clinical Sciences Building, Hope Hospital, Eccles Old Road, Salford, Manchester M6 8HD

R M Tillman

\section{Survey}

In view of the patient's comments regarding his colleagues, we decided to undertake a survey to establish if a particular occupational risk existed. Detailed postal questionnaires with stamped addressed envelopes were sent to 108 competition shearers who were all nationally graded above intermediate by the national shearing competitions committee. Sixty one completed forms were returned $(57 \%)$. In view of the itinerant nature of these people, we considered this a good response. There was no obvious difference between the responders and non-responders.

The mean age of respondents was 32 (range 2953). They had been shearing for an average of 13 years, and sheared an average of 14000 sheep per year (range 1000-45000).

The table shows the principal results of the survey regarding sensory disturbance in the hands. When these were analysed, the shearers fell into three groups according to the likely diagnoses.

Of the $\mathbf{4 6}$ shearers reporting severe parasthesia in one or both hands, $34(56 \%)$ gave a clear history of parasthesia on the radial side of the hand, suggesting a diagnosis of carpal tunnel syndrome. Twelve $(20 \%)$ described parasthesia only down the ulnar border suggesting a diagnosis of ulnar neuritis, and seven respondents $(11 \%)$ reported pain in the wrist with grating sensations, almost certainly tenosynovitis. Only eight shearers $(13 \%)$ denied any serious hand symptoms (fig 1).

As well as the patient described above, three further shearers had undergone surgical decompression of the carpal tunnel.

Sensory and motor disturbance in the hands of professional sheep shearers

\begin{tabular}{ll}
\hline Symptom & $\begin{array}{l}\text { No }(n=61) \\
(\%)\end{array}$ \\
\hline Parasthesia in one or both hands & $46(75)$ \\
Night time parasthesia & $24(39)$ \\
Parasthesia specifically brought on by shearing & $13(21)$ \\
Weakness of grip associated with parasthesia & $30(49)$ \\
Have seen doctor regarding this problem & $14(23)$ \\
Have had significant time off work due to this & $10(16)$ \\
Treated with injection or splint & $8(13)$ \\
Have undergone carpal tunnel release & $3(5)$ \\
\hline
\end{tabular}




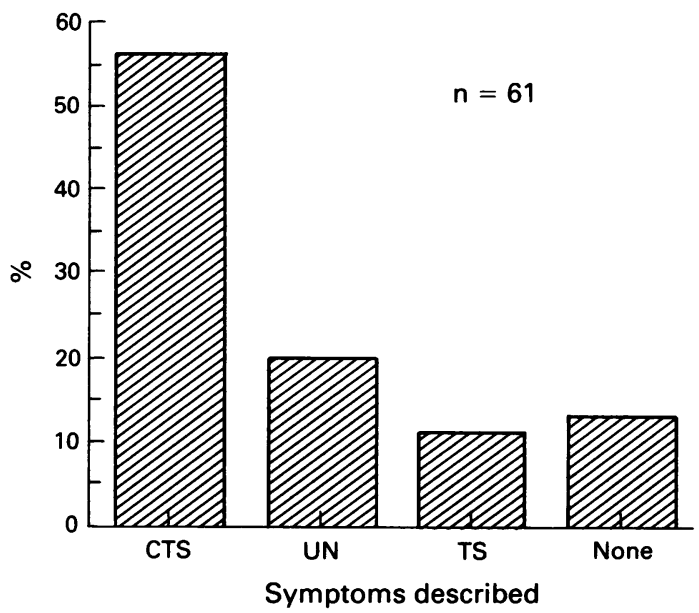

Figure 1 Probable diagnoses in shearers responding to the survey $C T S=$ Carpal tunnel syndrome; $U N=$ ulnar neuritis; $T S=$ tenosynovitis.

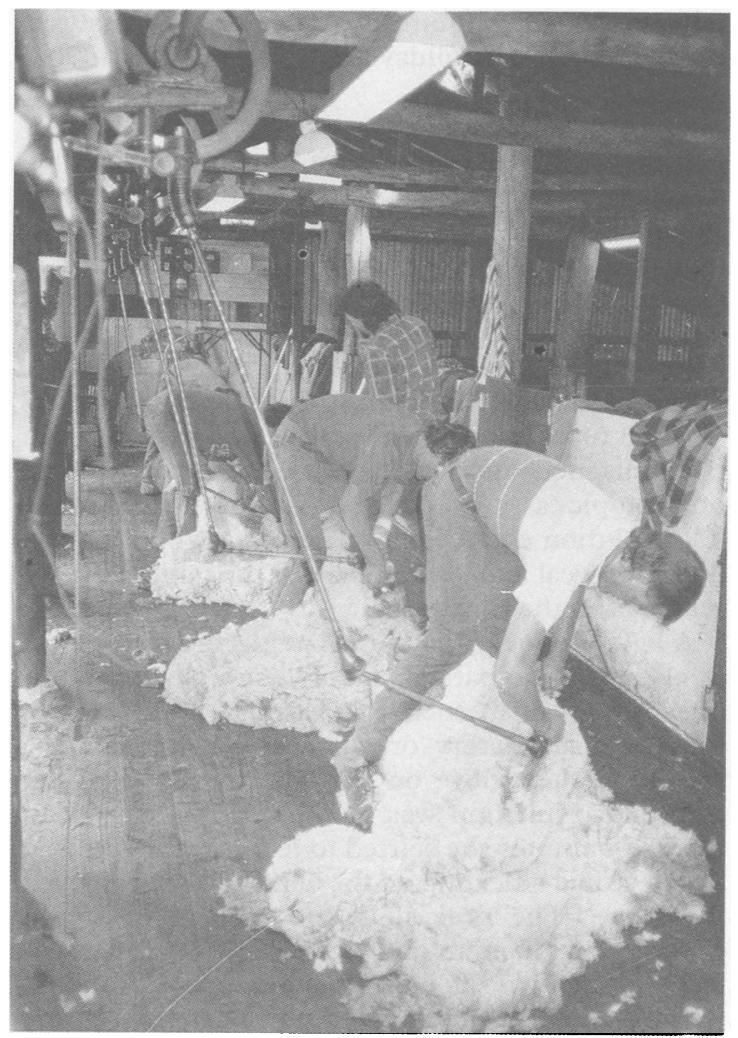

Figure 2 Sheep shearing is heavy manual work with great strain on the hands and wrists.

\section{Discussion}

Sheep shearing is an intensely physical occupation and the top professionals travel between the northern and southern hemispheres to work the year round.

Shearing involves holding a struggling sheep with one hand while pushing an electric cutter with the other (fig 2). As well as the pressure of pushing, the cutter vibrates, and the use of vibrating machinery as a cause of carpal tunnel syndrome has previously been highlighted in forestry workers ${ }^{6}$ and users of vibrating hand held tools. ${ }^{7}$

In this survey, $56 \%$ of respondents gave a history of symptoms strongly suggestive of carpal tunnel syndrome, and even if all non-respondents were asymptomatic, this would still give a prevalence of $31 \%$, far above that expected in the young adult male population in vew of the known preponderance of cases in the older female population. ${ }^{1}$ The figures may also be liable to underestimation as shearers severely troubled by carpal tunnel syndrome may have changed their occupation.

Most shearers are self employed and compensation for work related illness or injury may not be available, but this paper suggests that there may be an increased incidence of carpal tunnel syndrome in professional sheep shearers, and this diagnosis should be particularly borne in mind when these workers present with hand problems.

We thank Mr R B Smith FRCS, consultant orthopaedic surgeon, for permission to report this patient.

1 Phalen GS. The carpal tunnel syndrome. Clinical evaluation of 598 hands. Clin Orthop 1972;83:29-40.

2 Bauer ME. Carpal tunnel syndrome. An occupational risk to the dental hygienist. Journal of Dental Hygiene 1985;59:218-21.

3 Masear VR, Hayes JM, Hyde AG. An industrial cause of the carpal tunnel syndrome. J Hand Surg ( $\mathrm{Am}$ ) 1986;11:222-7.

4 Falck B, Aarnio P. Left-sided carpal tunnel syndrome in butchers. Scand J Work Environ Health 1983;9:291-7.

5 Punnett L, Robins JM, Wegman DH, Keyserling WM. Soft tissue disorders on the upper limbs of female garment workers. Scand J Work Environ Health 1985;1:417-25.

6 Koskimies K, Farkkila M, Pyykko I, Jantti V, Aatola S, Starck J, Inaba $\mathrm{R}$. Carpal tunnel syndrome in vibration disease. $\mathrm{Br} \mathrm{J}$ Ind Med 1990;47:411-6.

7 Wieslander G, Norback D, Gothe CJ, Juhlin L. Carpal tunnel syndrome (CTS) and exposure to vibration, repetitive wrist movements, and heavy manual work; a case referent study. $B r$ $J$ Ind Med 1989;46:43-7.

Accepted 2 December 1991. 